\title{
Operator Ideal of Cesaro Type Sequence Spaces Involving Lacunary Sequence
}

\author{
Awad A. Bakery ${ }^{1,2}$ \\ ${ }^{1}$ Department of Mathematics, Faculty of Science and Arts, King Abdulaziz University (KAU), \\ P.O. Box 80200, Khulais 21589, Saudi Arabia \\ ${ }^{2}$ Department of Mathematics, Faculty of Science, Ain Shams University, P.O. Box 1156, Abbassia, \\ Cairo 11566, Egypt
}

Correspondence should be addressed to Awad A. Bakery; awad_bakery@yahoo.com

Received 7 October 2013; Revised 13 January 2014; Accepted 15 January 2014; Published 26 February 2014

Academic Editor: Wenchang Sun

Copyright (C) 2014 Awad A. Bakery. This is an open access article distributed under the Creative Commons Attribution License, which permits unrestricted use, distribution, and reproduction in any medium, provided the original work is properly cited.

The aim of this paper is to give the sufficient conditions on the sequence space Ces $(\theta, p)$ defined in Lim (1977) such that the class of all bounded linear operators between any arbitrary Banach spaces with $n$th approximation numbers of the bounded linear operators in $\operatorname{Ces}(\theta, p)$ form an operator ideal.

\section{Introduction}

Most of the operator ideals in the class of Banach spaces or in the class of normed spaces in linear functional analysis are defined by different scalar sequence spaces. In [1], Pietsch studied the operator ideals generated by the approximation numbers and classical sequence space $\ell_{p}(0<p<\infty)$. In [2], Faried and bakery [3] have studied the ideal of all bounded linear operators between any arbitrary Banach spaces whose sequence of approximation numbers belonged to the generalized Cesáro sequence space and Orlicz sequence space $\ell_{M}$, when $M(t)=t^{p}, 0<p<\infty$; these results coincide with that known for the classical sequence space $\ell_{p}$. Bakery [4] has studied the operator ideals generated by the approximation numbers and generalized de La Vallée Poussin's mean $V(\lambda, p)$ defined by Şimşek et al. [5]; these results coincide with that known in [2] for the generalized Cesáro sequence space. By $L(X, Y)$, we indicate the space of all bounded linear operators from a normed space $X$ into a normed space $Y$. The set of nonnegative integers is denoted by $\mathbb{N}=\{0,1,2, \ldots\}$ and the real numbers by $\mathbb{R}$. By $\omega$, we denote the space of all real sequences. A map which assigns to every operator $T \in L(X, Y)$ a unique sequence $\left(s_{n}(T)\right)_{n=0}^{\infty}$ is called an $s$-function and the number $s_{n}(T)$ is called the $n$th $s$-numbers of $T$ if the following conditions are satisfied:

(a) $\|T\|=s_{0}(T) \geq s_{1}(T) \geq \cdots \geq 0$, for all $T \in L(X, Y)$,

(b) $s_{n}\left(T_{1}+T_{2}\right) \leq s_{n}\left(T_{1}\right)+\left\|T_{2}\right\|$, for all $T_{1}, T_{2} \in L(X, Y)$,

(c) $s_{n}(R S T) \leq\|R\| s_{n}(S)\|T\|$, for all $T \in L\left(X_{0}, X\right), S \in$ $L(X, Y)$, and $R \in L\left(Y, Y_{0}\right)$, where $X_{0}$ and $Y_{0}$ are normed spaces,

(d) $s_{n}(\lambda T)=|\lambda| s_{n}(T)$, for all $T \in L(X, Y), \lambda \in \mathbb{R}$,

(e) $\operatorname{rank}(T) \leq n$, if $s_{n}(T)=0$, for all $T \in L(X, Y)$,

(f)

$$
s_{r}\left(I_{n}\right)= \begin{cases}1 & \text { for } r<n \\ 0 & \text { for } r \geq n,\end{cases}
$$

where $I_{n}$ is the identity operator on the Euclidean space $\mathbb{R}^{n}$.

As examples of $s$-numbers, we mention that approximation numbers $\alpha_{n}(T)$, Gelfand numbers $c_{n}(T)$, Kolmogorov numbers $d_{n}(T)$, and Tichomirov numbers $d_{n}^{*}(T)$ are defined by

(I) $\alpha_{n}(T)=\inf \{\|T-A\|: A \in L(X, Y)$ and $\operatorname{rank}(A) \leq$ $n$ \}, 
(II) $c_{n}(T)=a_{n}\left(J_{Y} T\right)$, where $J_{Y}$ is a metric injection (a metric injection is a one to one operator with closed range and with norm equal to one) from the space $Y$ into a higher space $\ell^{\infty}(\Lambda)$ for a suitable index set $\Lambda$,

(III) $d_{n}(T)=\inf _{\operatorname{dim} Y \leq n} \sup _{\|x\| \leq 1} \inf _{y \in Y}\|T x-y\|$,

(IV) $d_{n}^{*}(T)=d_{n}\left(J_{Y} T\right)$

All these numbers satisfy the following condition:

(g) $s_{n+m}\left(T_{1}+T_{2}\right) \leq s_{n}\left(T_{1}\right)+s_{m}\left(T_{2}\right)$ for all $T_{1}, T_{2} \in L(X, Y)$.

The operator ideal $U(X, Y)$ is a subclass of $L(X, Y)$, where $X$ and $Y$ are Banach spaces such that its components satisfy the following conditions:

(i) $I_{K} \in U$, where $K$ denotes the 1-dimensional Banach space, where $U \subset L$;

(ii) if $T_{1}, T_{2} \in U(X, Y)$, then $\lambda_{1} T_{1}+\lambda_{2} T_{2} \in U(X, Y)$ for any scalars $\lambda_{1}, \lambda_{2}$;

(iii) if $F \in L\left(X_{0}, X\right), T \in U(X, Y)$, and $R \in L\left(Y, Y_{0}\right)$, then $R T F \in U\left(X_{0}, Y_{0}\right)$; see $[1,6,7]$.

By a lacunary sequence $(\theta)=\left(k_{n}\right)$, where $k_{-1}=0$, we mean an increasing sequence of nonnegative integers with $k_{n}-k_{n-1} \rightarrow$ 0 as $n \rightarrow \infty$. The intervals determined by $\theta$ are denoted by $I_{n}=\left[k_{n-1}, k_{n}\right)$. We write $h_{n}=k_{n}-k_{n-1}$. The space of lacunary strongly convergent sequences $N_{\theta}$ was defined by Freedman and denoted by

$$
N_{\theta}=\left\{x=\left(x_{k}\right): \lim _{n \rightarrow \infty} \frac{1}{h_{n}} \sum_{k \in I_{n}}\left|x_{k}-l\right|=0, \text { for some } l\right\} \text {. }
$$

It is well known that there exists very close connection between the space of lacunary strongly convergent sequences and the space of strongly Cesaro summable sequences. This connection can be found in [8-10].

For a sequence $p=\left(p_{n}\right)$ of positive real numbers with $p_{n} \geq 1$, for all $n \in \mathbb{N}$, the generalized Cesaro sequence space is defined by

$$
\operatorname{Ces}(\theta, p)=\left\{x=\left(x_{k}\right) \in \omega: \rho(\lambda x)<\infty \text { for some } \lambda>0\right\} \text {, }
$$

where $\rho(x)=\sum_{n=0}^{\infty}\left(\left(1 / h_{n}\right) \sum_{k \in I_{n}}\left|x_{k}\right|\right)^{p_{n}}$.

The space $\operatorname{Ces}(\theta, p)$ is a Banach space with the norm $\|x\|=$ $\inf \{\lambda>0: \rho(x / \lambda) \leq 1\}$.

If $p=\left(p_{n}\right)$ is bounded, we can simply write $\operatorname{Ces}(\theta, p)=$ $\left\{x \in \omega: \sum_{n=0}^{\infty}\left(\left(1 / h_{n}\right) \sum_{k \in I_{n}}\left|x_{k}\right|\right)^{p_{n}}<\infty\right\}$. Also, some geometric properties of $\operatorname{Ces}(\theta, p)$ have been studied in [11-13].

Remarks. (1) If $\theta=2^{n+1}-1$, then we obtain the sequences space

$$
\operatorname{Ces}(p)=\left\{x \in \omega: \sum_{n=0}^{\infty}\left(\frac{1}{2^{n}} \sum_{k=2^{n}-1}^{2^{n+1}-2}\left|x_{k}\right|\right)^{p_{n}}<\infty\right\},
$$

studied in $[12,13]$.
(2) If $\theta=2^{n+1}-1$ and $p_{n}=p$, for all $n \in \mathbb{N}$, then we obtain the sequences space $\mathrm{Ces}_{p}$ studied in [14].

The idea of the paper is the following. We proceed in the following way: given a scalar sequence space $\operatorname{Ces}(\theta, p)$, a pair of Banach spaces $X$ and $Y$, the space of bounded operators $L(X, Y)$, and the approximation $s$-numbers $\alpha_{n}(T)$, $T \in L(X, Y)$, and $n \in \mathbb{N}$, we define the space $U_{\operatorname{Ces}(\theta, p)}^{\text {app }}(X, Y)$. Then, we study the following two problems:

Problem A (a linear problem). When (for which $\operatorname{Ces}(\theta, p)$ ) $U_{\operatorname{Ces}(\theta, p)}^{\text {app }}$ is an operator ideal.

Problem B (topological problems). When the ideal of the finite range operators in the class of Banach spaces is dense in $U_{\operatorname{Ces}(\theta, p)}^{\text {app }}$ and completeness of the components of the ideal.

Throughout this paper, the sequence $\left(p_{n}\right)$ is a bounded sequence of positive real numbers with the following:

(a1) the sequence $\left(p_{n}\right)$ of positive real numbers is increasing and bounded with $\lim _{n \rightarrow \infty} \sup p_{n}<\infty$ and $\lim _{n \rightarrow \infty} \inf p_{n}>1$,

(a2) the sequence $\left(h_{n}\right)$ is a nondecreasing sequence of positive real numbers tending to $\infty$, with $\sum_{n=0}^{\infty}\left(1 / h_{n}\right)^{p_{n}}<$ $\infty$.

Also, we define $e_{i}=(0,0, \ldots, 1,0,0, \ldots)$, where 1 appears at the $i$ th place for all $i \in \mathbb{N}$.

Recently different classes of paranormed sequence spaces have been introduced and their different properties have been investigated by Et et al. [15], Tripathy and Dutta [16, 17], and Tripathy and Borgogain [18], and see also [19-23].

The following well-known inequality will be used throughout the paper. For any bounded sequence of positive numbers $\left(p_{n}\right),\left|a_{n}+b_{n}\right|^{p_{n}} \leq 2^{H-1}\left(\left|a_{n}\right|^{p_{n}}+\left|b_{n}\right|^{p_{n}}\right), H=\sup _{n} p_{n}$ and $p_{n} \geq 1$ for all $n \in \mathbb{N}$. See [24].

\section{Preliminary and Notation}

Definition 1. A class of linear sequence spaces $E$ is called a special space of sequences (sss) having three properties:

(1) $E$ is a linear space and $e_{n} \in E$ for each $n \in \mathbb{N}$;

(2) if $x \in \omega, y \in E$, and $\left|x_{n}\right| \leq\left|y_{n}\right|$ for all $n \in \mathbb{N}$, then $x \in E$; "that is, $E$ is solid;"

(3) if $\left(x_{n}\right)_{n=0}^{\infty} \in E$, then $\left(x_{[n / 2]}\right)_{n=0}^{\infty}=$ $\left(x_{0}, x_{0}, x_{1}, x_{1}, x_{2}, x_{2}, \ldots\right) \in E$, where $[n / 2]$ denotes the integral part of $n / 2$.

Example 2. $\ell_{p}$ is a special space of sequences for $0<p<\infty$.

Example 3. Ces ${ }_{p}$ defined in [14] is a special space of sequences for $1<p<\infty$.

Example 4. Let $M$ be an Orlicz function satisfying $\Delta_{2}$ condition; then $\ell_{M}$ is a special space of sequences. 
Example 5. Ces( $p)$ studied in [3] is a special space of sequences, if $\left(p_{n}\right)$ is an increasing sequence of positive real numbers, $\lim _{n \rightarrow \infty} \sup p_{n}<\infty$ and $\lim _{n \rightarrow \infty} \inf p_{n}>1$.

Example 6. $V(\lambda, p)$ is a special space of sequences, if the following conditions are satisfied:

(1) the sequence $\left(p_{n}\right)$ of positive real numbers is increasing and bounded with $\lim _{n \rightarrow \infty} \sup p_{n}<\infty$ and $\lim _{n \rightarrow \infty} \inf p_{n}>1$;

(2) the sequence $\left(\lambda_{n}\right)$ is a nondecreasing sequence of positive real numbers tending to $\infty, \lambda_{0}=1$ and $\lambda_{n+1} \leq \lambda_{n}+1$ with $\sum_{n=0}^{\infty}\left(1 / \lambda_{n}\right)^{p_{n}}<\infty$.

Definition 7. $U_{E}^{\text {app }}:=\left\{U_{E}^{\text {app }}(X, Y) ; X\right.$ and $Y$ are Banach spaces $\}$, where $U_{E}^{\mathrm{app}}(X, Y):=\left\{T \in L(X, Y):\left(\alpha_{n}(T)\right)_{n=0}^{\infty} \in E\right\}$.

We state the following result without proof.

Theorem 8. $U_{E}^{a p p}$ is an operator ideal if $E$ is a special space of sequences (sss).

We study here the operator ideals generated by the approximation numbers and the sequence space $\operatorname{Ces}(\theta, p)$ which are involving Lacunary sequence.

\section{Main Results}

Theorem 9. $U_{c e s(\theta, p)}^{a p p}$ is an operator ideal, if conditions (a1) and (a2) are satisfied.

Proof. (1-i) Let $x, y \in \operatorname{Ces}(\theta, p)$; since $\sum_{n=0}^{\infty}((1 /$ $\left.\left.h_{n}\right) \sum_{k \in I_{n}}\left|x_{k}+y_{k}\right|\right)^{p_{n}} \leq 2^{H-1}\left(\sum_{n=0}^{\infty}\left(\left(1 / h_{n}\right) \sum_{k \in I_{n}}\left|x_{k}\right|\right)^{p_{n}}+\right.$ $\left.\sum_{n=0}^{\infty}\left(\left(1 / h_{n}\right) \sum_{k \in I_{n}}\left|y_{k}\right|\right)^{p_{n}}\right), H=\sup _{n} p_{n}$, then $x+y \in$ $\operatorname{Ces}(\theta, p)$.

(1-ii) Let $\lambda \in \mathbb{R}, x \in \operatorname{Ces}(\theta, p)$; then $\sum_{n=0}^{\infty}((1 /$ $\left.\left.h_{n}\right) \sum_{k \in I_{n}}\left|\lambda x_{k}\right|\right)^{p_{n}} \leq \sup _{n}|\lambda|^{p_{n}} \sum_{n=0}^{\infty}\left(\left(1 / h_{n}\right) \sum_{k \in I_{n}}\left|x_{k}\right|\right)^{p_{n}}<$ $\infty$; we get $\lambda x \in \operatorname{Ces}(\theta, p)$, from (1-i) and (1-ii), and $\operatorname{Ces}(\theta, p)$ is a linear space.

To prove that $e_{m} \in \operatorname{Ces}(\theta, p)$ for each $m \in \mathbb{N}$, since $\sum_{n=0}^{\infty}\left(1 / h_{n}\right)^{p_{n}}<\infty$. So, we get

$$
\rho\left(e_{m}\right)=\sum_{n=m}^{\infty}\left(\frac{1}{h_{n}} \sum_{k \in I_{n}}\left|e_{m}(k)\right|\right)^{p_{n}}=\sum_{n=m}^{\infty}\left(\frac{1}{h_{n}}\right)^{p_{n}}<\infty .
$$

Hence, $e_{m} \in \operatorname{Ces}(\theta, p)$.

(2) Let $\left|x_{n}\right| \leq\left|y_{n}\right|$ for each $n \in \mathbb{N}$; then $\sum_{n=0}^{\infty}\left(\left(1 / h_{n}\right) \sum_{k \in I_{n}}\left|x_{k}\right|\right)^{p_{n}} \leq \sum_{n=0}^{\infty}\left(\left(1 / h_{n}\right) \sum_{k \in I_{n}}\left|y_{k}\right|\right)^{p_{n}}$, since $y \in \operatorname{Ces}(\theta, p)$. Thus, $x \in \operatorname{Ces}(\theta, p)$.

(3) Let $\left(x_{n}\right) \in \operatorname{Ces}(\theta, p)$; then we have

$$
\begin{aligned}
& \sum_{n=0}^{\infty}\left(\frac{1}{h_{n}} \sum_{k \in I_{n}}\left|x_{[k / 2]}\right|\right)^{p_{n}} \\
& =\sum_{n=0}^{\infty}\left(\frac{1}{h_{2 n}} \sum_{k \in I_{2 n}}\left|x_{[k / 2]}\right|\right)^{p_{2 n}}+\sum_{n=0}^{\infty}\left(\frac{1}{h_{2 n+1}} \sum_{k \in I_{2 n+1}}\left|x_{[k / 2]}\right|\right)^{p_{2 n+1}}
\end{aligned}
$$

$$
\begin{aligned}
\leq & \sum_{n=0}^{\infty}\left(\frac{1}{h_{2 n}}\left(\left(\sum_{k \in I_{n}} 2\left|x_{k}\right|\right)+\left|x_{n}\right|\right)\right)^{p_{n}} \\
& +\sum_{n=0}^{\infty}\left(\frac{1}{h_{2 n+1}}\left(\sum_{k \in I_{n}} 2\left|x_{k}\right|\right)\right)^{p_{n}} \\
\leq & 2^{H-1}\left(\sum_{n=0}^{\infty}\left(\frac{1}{h_{n}}\left(2 \sum_{k \in I_{n}}\left|x_{k}\right|\right)\right)^{p_{n}}+\sum_{n=0}^{\infty}\left(\frac{1}{h_{n}} \sum_{k \in I_{n}}\left|x_{k}\right|\right)^{p_{n}}\right) \\
& \left.+2^{H} \sum_{n=0}^{\infty}\left(\frac{1}{h_{n}} \sum_{k \in I_{n}}\left|x_{k}\right|\right)^{p_{n}}\right) \\
\leq & 2^{H-1}\left(2^{H}+1\right) \sum_{n=0}^{\infty}\left(\frac{1}{h_{n}} \sum_{k \in I_{n}}\left|x_{k}\right|\right)^{p_{n}} \\
& +2^{H} \sum_{n=0}^{\infty}\left(\frac{1}{h_{n}} \sum_{k \in I_{n}}\left|x_{k}\right|\right)^{p_{n}} \\
\leq & \left(2^{2 H-1}+2^{H-1}+2^{H}\right) \sum_{n=0}^{\infty}\left(\frac{1}{h_{n}} \sum_{k \in I_{n}}\left|x_{k}\right|\right)^{p_{n}}<\infty .
\end{aligned}
$$

So, $\left(x_{[n / 2]}\right)_{n=0}^{\infty} \in \operatorname{Ces}(\theta, p)$.

Hence, from Theorem 8 , it follows that $U_{\operatorname{Ces}(\theta, p)}^{\text {app }}$ is an operator ideal.

Corollary 10. $U_{c e s(p)}^{a p p}$ is an operator ideal if $\left(p_{n}\right)$ is an increasing sequence of positive real numbers, $\lim _{n \rightarrow \infty} \sup p_{n}<\infty$ and $\lim _{n \rightarrow \infty} \inf p_{n}>1$

Corollary 11. $U_{c e s_{p}}^{a p p}$ is an operator ideal if $1<p<\infty$.

Theorem 12. The linear space $F(X, Y)$ is dense in $U_{c e s(\theta, p)}^{a p p}(X$, $Y)$ if conditions (a1) and (a2) are satisfied.

Proof. First, we show that every finite mapping $T \in F(X, Y)$ belongs to $U_{\operatorname{Ces}(\theta, p)}^{\text {app }}(X, Y)$. Since $e_{m} \in \operatorname{Ces}(\theta, p)$ for each $m \in$ $\mathbb{N}$ and $\operatorname{Ces}(\theta, p)$ is a linear space, then for every finite mapping $T \in F(X, Y)$, that is, the sequence $\left(\alpha_{n}(T)\right)_{n=0}^{\infty}$ contains only finitely many numbers different from zero. Now, we prove that $U_{\operatorname{Ces}(\theta, p)}^{\text {app }}(X, Y) \subseteq \overline{F(X, Y)}$. On taking $T \in U_{\operatorname{Ces}(\theta, p)}^{\text {app }}(X, Y)$, we obtain $\left(\alpha_{n}(T)\right)_{n=0}^{\infty} \in \operatorname{Ces}(\theta, p)$, and since $\rho\left(\left(\alpha_{n}(T)\right)_{n=0}^{\infty}\right)<$ $\infty$, let $\varepsilon \in(0,1)$; then there exists a natural number $s>0$ such that $\rho\left(\left(\alpha_{n}(T)\right)_{n=s}^{\infty}\right)<\varepsilon / 2^{H+2} \delta c$ for some $c \geq 1$, where $\delta=\max \left\{1, \sum_{n=s}^{\infty}\left(1 / h_{n}\right)^{p_{n}}\right\}$. Since $\alpha_{n}(T)$ is decreasing for each $n \in \mathbb{N}$, we get

$$
\begin{aligned}
\sum_{n=s+1}^{2 s}\left(\frac{1}{h_{n}} \sum_{k \in I_{n}} \alpha_{2 s}(T)\right)^{p_{n}} & \leq \sum_{n=s+1}^{2 s}\left(\frac{1}{h_{n}} \sum_{k \in I_{n}} \alpha_{n}(T)\right)^{p_{n}} \\
& \leq \sum_{n=s}^{\infty}\left(\frac{1}{h_{n}} \sum_{k \in I_{n}} \alpha_{k}(T)\right)^{p_{n}}<\frac{\varepsilon}{2^{H+2} \delta c} ;
\end{aligned}
$$


then there exists $A \in F_{2 s}(X, Y)$ and $\operatorname{rank}(A) \leq 2 s$ with

$$
\begin{aligned}
\sum_{n=2 s+1}^{3 s}\left(\frac{1}{h_{n}} \sum_{k \in I_{n}}\|T-A\|\right)^{p_{n}} & \leq \sum_{n=s+1}^{2 s}\left(\frac{1}{h_{n}} \sum_{k \in I_{n}}\|T-A\|\right)^{p_{n}} \\
& <\frac{\varepsilon}{2^{H+2} \delta c}
\end{aligned}
$$

and since $\left(p_{n}\right)$ is a bounded sequence of positive real numbers, so on considering

$$
\sup _{n=s}^{\infty}\left(\sum_{k \in I_{s}}\|T-A\|\right)^{p_{n}}<\frac{\varepsilon}{2^{H} \delta}
$$

also $\alpha_{n}(T)=\inf \{\|T-A\|: A \in L(X, Y)$ and $\operatorname{rank}(A) \leq n\}$. Then, there exists a natural number $N>0, A_{N}$ with rank $\left(A_{N}\right) \leq N$ and $\left\|T-A_{N}\right\| \leq 2 \alpha_{N}(T)$. Since $\alpha_{n}(T) \stackrel{n \rightarrow \infty}{\longrightarrow} 0$, then $\left\|T-A_{N}\right\| \stackrel{N \rightarrow \infty}{\longrightarrow} 0$, so we can take

$$
\sum_{n=0}^{s}\left(\frac{1}{h_{n}} \sum_{k \in I_{n}}\|T-A\|\right)^{p_{n}}<\frac{\varepsilon}{2^{H+3} \delta c}
$$

Since $\left(p_{n}\right)$ is an increasing sequence, by using $(7),(8),(9)$, and (10), we acquire

$$
\begin{aligned}
d(T, A) & =\rho\left(\alpha_{n}(T-A)\right)_{n=0}^{\infty} \\
= & \sum_{n=0}^{3 s-1}\left(\frac{1}{h_{n}} \sum_{k \in I_{n}} \alpha_{k}(T-A)\right)^{p_{n}}+\sum_{n=3 s}^{\infty}\left(\frac{1}{h_{n}} \sum_{k \in I_{n}} \alpha_{k}(T-A)\right)^{p_{n}} \\
\leq & \sum_{n=0}^{3 s}\left(\frac{1}{h_{n}} \sum_{k \in I_{n}}\|T-A\|\right)^{p_{n}}+\sum_{n=s}^{\infty}\left(\frac{1}{h_{n}} \sum_{k \in I_{n+2 s}} \alpha_{k}(T-A)\right)^{p_{n+2 s}} \\
\leq & 3 \sum_{n=0}^{s}\left(\frac{1}{h_{n}} \sum_{k \in I_{n}}\|T-A\|\right)^{p_{n}} \\
& +\sum_{n=s}^{\infty}\left(\frac{1}{h_{n}} \sum_{k \in I_{2 s-1}} \alpha_{k}(T-A)+\frac{1}{h_{n}} \sum_{k \in I_{n+2 s} \backslash I_{2 s-1}} \alpha_{k}(T-A)\right)^{p_{n}} \\
\leq & \left.3 \sum_{n=0}^{s}\left(\frac{1}{h_{n}} \sum_{k \in I_{n}}\|T-A\|\right)^{p_{n}}\right)_{n=s}^{\infty}\left(\frac{1}{h_{n}} \sum_{k \in I_{n+2 s} \backslash I_{2 s-1}} \alpha_{k}(T-A)\right)^{p_{n}} \\
& +2 \\
& 2\left(\sum _ { n = s } ^ { \infty } \left(\frac{1}{h_{n}} \sum_{k \in I_{2 s-1}} \alpha_{k}(T-A)\right.\right.
\end{aligned}
$$

$$
\begin{aligned}
& \leq 3 \sum_{n=0}^{s}\left(\frac{1}{h_{n}} \sum_{k \in I_{n}}\|T-A\|\right)^{p_{n}} \\
& +2^{H-1}\left(\sum_{n=s}^{\infty}\left(\frac{1}{h_{n}} \sum_{k \in I_{s}}\|T-A\|\right)^{p_{n}}\right. \\
& \left.+\sum_{n=s}^{\infty}\left(\frac{1}{h_{n}} \sum_{k \in I_{n}} \alpha_{k+2 s}(T-A)\right)^{p_{n}}\right) \\
& \leq 3 \sum_{n=0}^{s}\left(\frac{1}{h_{n}} \sum_{k=0}^{n}\|T-A\|\right)^{p_{n}} \\
& +2^{H-1} \sup _{n=s}^{\infty}\left(\sum_{k \in I_{s}}\|T-A\|\right)^{p_{n}} \sum_{n=s}^{\infty}\left(\frac{1}{h_{n}}\right)^{p_{n}} \\
& +2^{H-1} \sum_{n=s}^{\infty}\left(\frac{1}{h_{n}} \sum_{k \in I_{n}} \alpha_{k}(T)\right)^{p_{n}}<\varepsilon .
\end{aligned}
$$

This completes the proof.

Definition 13. A subclass of the special space of sequences called premodular special space of sequences characterized for the existence of a function $\rho: E \rightarrow[0, \infty)$, closely connected with the notion of modular but without assumption of the convexity, which satisfies the following:

(i) $\rho(x) \geq 0$ for all $x \in E_{\rho}$ and $\rho(x)=0 \Leftrightarrow x=0$, where 0 is the zero element of $E$;

(ii) there exists a constant $N \geq 1$ such that $\rho(\lambda x) \leq$ $N|\lambda| \rho(x)$ for all values of $x \in E$ and for any scalar $\lambda$;

(iii) for some numbers $K \geq 1$, we have the inequality $\rho(x+$ $y) \leq K(\rho(x)+\rho(y))$ for all $x, y \in E$;

(iv) if $\left|x_{n}\right| \leq\left|y_{n}\right|$ for all $n \in \mathbb{N}$, then $\rho\left(\left(x_{n}\right)\right) \leq \rho\left(\left(y_{n}\right)\right)$;

(v) for some numbers $K_{0} \geq 1$, we have the inequality $\rho\left(\left(x_{n}\right)\right) \leq \rho\left(\left(x_{[n / 2]}\right)\right) \leq K_{0} \rho\left(\left(x_{n}\right)\right) ;$

(vi) for each $x=(x(i))_{i=0}^{\infty} \in E$, there exists $s \in \mathbb{N}$ such that $\rho(x(i))_{i=s}^{\infty}<\infty$; this means the set of all finite sequences is $\rho$-dense in $E$;

(vii) for any $\lambda>0$, there exists a constant $\zeta>0$ such that $\rho(\lambda, 0,0,0, \ldots) \geq \zeta \lambda \rho(1,0,0,0, \ldots)$.

It is obvious from condition (ii) that $\rho$ is continuous at the zero element of $E$. The function $\rho$ defines a metrizable topology in $E$ endowed with this topology which is denoted by $E_{\rho}$. 
Example 14. $\ell_{p}$ is a premodular special space of sequences for $0<p<\infty$ with $\rho(x)=\sum_{n=0}^{\infty}\left|x_{n}\right|^{p}$.

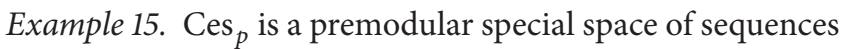
for $1<p<\infty$ with $\rho(x)=\sum_{n=0}^{\infty}\left((1 /(n+1)) \sum_{k=0}^{n}\left|x_{n}\right|\right)^{p}$.

Example 16. Let $M$ be an Orlicz function satisfying $\Delta_{2}$-condition; then $\ell_{M}$ is a pre-modular special space of sequences with $\rho(x)=\sum_{n=0}^{\infty} M\left(\left|x_{n}\right|\right)$.

Example 17. If $\left(p_{n}\right)$ is an increasing sequence of positive real numbers, $\lim _{n \rightarrow \infty} \sup p_{n}<\infty$ and $\lim _{n \rightarrow \infty} \inf p_{n}>1$, then $\operatorname{Ces}(p)$ is a premodular special space of sequences for $1<p<$ $\infty$, with $\rho(x)=\sum_{n=0}^{\infty}\left((1 /(n+1)) \sum_{k=0}^{n}\left|x_{n}\right|\right)^{p_{k}}$.

Example 18. If the following conditions are satisfied:

(1) the sequence $\left(p_{n}\right)$ of positive real numbers is increasing and bounded with $\limsup p_{n}<\infty$ and $\lim \inf p_{n}>1$;

(2) the sequence $\left(\lambda_{n}\right)$ is a nondecreasing sequence of positive real numbers tending to $\infty, \lambda_{0}=1$, and $\lambda_{n+1} \leq \lambda_{n}+1$ with $\sum_{n=0}^{\infty}\left(1 / \lambda_{n}\right)^{p_{n}}<\infty$; then $V(\lambda, p)$ is a premodular special space of sequences.

Theorem 19. $\operatorname{Ces}(\theta, p)$ with $\rho(x)=$ $\sum_{n=0}^{\infty}\left(\left(1 / h_{n}\right) \sum_{k \in I_{n}}\left|x_{n}\right|\right)^{p_{n}}$ is a premodular special space of sequences, if conditions (a1) and (a2) are contented.

Proof. (i) Clearly, $\rho(x) \geq 0$ and $\rho(x)=0 \Leftrightarrow x=0$.

(ii) Since $\left(p_{n}\right)$ is bounded, then there exists a constant $N \geq$ 1 such that $\rho(\lambda x) \leq N|\lambda| \rho(x)$ for all values of $x \in E$ and for any scalar $\lambda$.

(iii) For some numbers $K=\max \left(1,2^{H-1}\right) \geq 1$, we have the inequality $\rho(x+y) \leq K(\rho(x)+\rho(y))$ for all $x, y \in$ $\operatorname{Ces}(\theta, p)$.

(iv) Let $\left|x_{n}\right| \leq\left|y_{n}\right|$ for all $n \in \mathbb{N}$; then $\sum_{n=0}^{\infty}\left(\left(1 / h_{n}\right) \sum_{k \in I_{n}}\left|x_{n}\right|\right)^{p_{n}} \leq \sum_{n=0}^{\infty}\left(\left(1 / h_{n}\right) \sum_{k \in I_{n}}\left|y_{n}\right|\right)^{p_{n}}$.

(v) There exist some numbers $K_{0}=2^{H-1}\left(2^{H}+1\right)+2^{H} \geq 1$; by using (iv), we have the inequality $\rho\left(\left(x_{n}\right)\right) \leq \rho\left(\left(x_{[n / 2]}\right)\right) \leq$ $K_{0} \rho\left(\left(x_{n}\right)\right)$.

(vi) It is clear that the set of all finite sequences is $\rho$-dense in $\operatorname{Ces}(\theta, p)$.

(vii) For any $\lambda>0$, there exists a constant $0<\zeta<\lambda^{p_{0}-1}$ such that $\rho(\lambda, 0,0,0, \ldots) \geq \zeta \lambda \rho(1,0,0,0, \ldots)$.

Theorem 20. Let $X$ be a normed space, let $Y$ be a Banach space, and let conditions (a1) and (a2) be satisfied; then $U_{\text {ces }(\theta, p)}^{a p p}(X, Y)$ is complete.

Proof. Let $\left(T_{m}\right)$ be a Cauchy sequence in $U_{\operatorname{Ces}(\theta, p)}^{\text {app }}(X, Y)$. Since $\operatorname{Ces}(\theta, p)$ with $\rho(x)=\sum_{n=0}^{\infty}\left(\left(1 / h_{n}\right) \sum_{k \in I_{n}}\left|x_{n}\right|\right)^{p_{n}}$ is a premodular special space of sequences, then, by using condition (vii) and since $U_{\operatorname{Ces}(\theta, p)}^{\text {app }}(X, Y) \subseteq L(X, Y)$, we have $\rho\left(\left(\alpha_{n}\left(T_{i}-T_{j}\right)\right)_{n=0}^{\infty}\right) \geq \rho\left(\alpha_{0}\left(T_{i}-T_{j}\right), 0,0,0, \ldots\right)=\rho\left(\| T_{i}-\right.$ $\left.T_{j} \|, 0,0,0, \ldots\right) \geq \zeta\left\|T_{i}-T_{j}\right\| \rho(1,0,0,0, \ldots)$, then $\left(T_{m}\right)$ is also a Cauchy sequence in $L(X, Y)$. Since the space $L(X, Y)$ is a Banach space, then there exists $T \in L(X, Y)$ such that
$\left\|T_{m}-T\right\| \stackrel{m \rightarrow \infty}{\longrightarrow} 0$ and since $\left(\alpha_{n}\left(T_{m}\right)\right)_{n=0}^{\infty} \in E$ for all $m \in \mathbb{N}$, $\rho$ is continuous at 0 and, using (iii), we have

$$
\begin{aligned}
\rho\left(\alpha_{n}(T)\right)_{n=0}^{\infty} & =\rho\left(\alpha_{n}\left(T-T_{m}+T_{m}\right)\right)_{n=0}^{\infty} \\
& \leq K \rho\left(\alpha_{[n / 2]}\left(T_{m}-T\right)\right)_{n=0}^{\infty}+K \rho\left(\alpha_{[n / 2]}\left(T_{m}\right)\right)_{n=0}^{\infty} \\
& \leq K \rho\left(\left(\left\|T_{m}-T\right\|\right)_{n=0}^{\infty}\right)+K \rho\left(\alpha_{n}\left(T_{m}\right)\right)_{n=0}^{\infty}<\varepsilon
\end{aligned}
$$

for some $K \geq 1$.

Hence, $\left(\alpha_{n}(T)\right)_{n=0}^{\infty} \in \operatorname{Ces}(\theta, p)$ as $\operatorname{such} T \in U_{\operatorname{Ces}(\theta, p)}^{\mathrm{app}}(X, Y)$.

Corollary 21. Let $X$ be a normed space, let $Y$ be a Banach space, and let $\left(p_{n}\right)$ be an increasing sequence of positive real numbers with $\lim _{n \rightarrow \infty}$ sup $p_{n}<\infty$ and $\lim _{n \rightarrow \infty}$ inf $p_{n}>1$; then $U_{\text {ces }}^{a p p)}(X, Y)$ is complete.

Corollary 22. Let $X$ be a normed space, let $Y$ be a Banach space, let and $\left(p_{n}\right)$ be an increasing sequence of positive real numbers with $1<p<\infty$; then $U_{\text {ces }}^{a p p}(X, Y)$ is complete.

\section{Conflict of Interests}

The author declares that there is no conflict of interests regarding the publication of this paper.

\section{Acknowledgments}

This work was funded by the Deanship of Scientific Research (DSR), King Abdulaziz University, Jeddah, under Grant no. 857-007-D1434. The author, therefore, acknowledges with thanks DSR technical and financial support. Moreover, the author is most grateful to the editor and anonymous referee for careful reading of the paper and valuable suggestions which helped in improving an earlier version of it.

\section{References}

[1] A. Pietsch, Operator Ideals, vol. 20 of North-Holland Mathematical Library, North-Holland Publishing, Amsterdam, The Netherlands, 1980.

[2] N. F. Mohamed and A. A. Bakery, "Mappings of type Orlicz and generalized Cesáro sequence space," Journal of Inequalities and Applications, vol. 2013, article 186, 9 pages, 2013.

[3] W. Sanhan and S. Suantai, "On $k$-nearly uniform convex property in generalized Cesàro sequence spaces," International Journal of Mathematics and Mathematical Sciences, no. 57, pp. 3599-3607, 2003.

[4] A. A. Bakery, "Mappings of type generalized de La Vallée Poussin's mean," Journal of Inequalities and Applications, vol. 2013, article 518, 2013.

[5] N. Şimşek, E. Savaş, and V. Karakaya, "Some geometric and topological properties of a new sequence space defined by de la Vallée-Poussin mean," Journal of Computational Analysis and Applications, vol. 12, no. 4, pp. 768-779, 2010.

[6] N. J. Kalton, "Spaces of compact operators," Mathematische Annalen, vol. 208, pp. 267-278, 1974. 
[7] Å. Lima and E. Oja, "Ideals of finite rank operators, intersection properties of balls, and the approximation property," Studia Mathematica, vol. 133, no. 2, pp. 175-186, 1999.

[8] G. Das and B. K. Patel, "Lacunary distribution of sequences," Indian Journal of Pure and Applied Mathematics, vol. 20, no. 1, pp. 64-74, 1989.

[9] A. R. Freedman, J. J. Sember, and M. Raphael, "Some Cesàrotype summability spaces," Proceedings of the London Mathematical Society, vol. 37, no. 3, pp. 508-520, 1978.

[10] Mursaleen and T. A. Chishti, "Some spaces of lacunary sequences defined by the modulus," Journal of Analysis, vol. 4, pp. 153-159, 1996.

[11] K. P. Lim, "Matrix transformation on certain sequence spaces," Tamkang Journal of Mathematics, vol. 8, no. 2, pp. 213-220, 1977.

[12] K. P. Lim, "Matrix transformation in the Cesàro sequence spaces," Kyungpook Mathematical Journal, vol. 14, pp. 221-227, 1974.

[13] T. Bilgin, "The sequence space $\operatorname{Ces}(s, p)$ and related matrix transformations," The Punjab University Journal of Mathematics, vol. 30, pp. 67-77, 1997.

[14] J.-S. Shiue, “On the Cesáro sequence spaces," Tamkang Journal of Mathematics, vol. 1, no. 1, pp. 19-25, 1970.

[15] M. Et, Y. Altin, B. Choudhary, and B. C. Tripathy, "On some classes of sequences defined by sequences of Orlicz functions," Mathematical Inequalities \& Applications, vol. 9, no. 2, pp. 335342, 2006.

[16] B. C. Tripathy and H. Dutta, "On some new paranormed difference sequence spaces defined by Orlicz functions," Kyungpook Mathematical Journal, vol. 50, no. 1, pp. 59-69, 2010.

[17] B. C. Tripathy and H. Dutta, "On some lacunary difference sequence spaces defined by a sequence of Orlicz functions and $q$-lacunary $\triangle_{m}^{n}$-statistical convergence," Analele Stiintifice ale Universitatii Ovidius Constanta, Seria Matematicaa, vol. 20, no. 1, pp. 417-430, 2012.

[18] B. C. Tripathy and S. Borgohain, "Some classes of difference sequence spaces of fuzzy real numbers defined by orlicz function," Advances in Fuzzy Systems, vol. 2011, Article ID 216414, 6 pages, 2011.

[19] D. Rath and B. C. Tripathy, "Matrix maps on sequence spaces associated with sets of integers," Indian Journal of Pure and Applied Mathematics, vol. 27, no. 2, pp. 197-206, 1996.

[20] B. C. Tripathy and M. Sen, "On generalized statistically convergent sequences," Indian Journal of Pure and Applied Mathematics, vol. 32, no. 11, pp. 1689-1694, 2001.

[21] B. C. Tripathy and P. Chandra, "On some generalized difference paranormed sequence spaces associated with multiplier sequence defined by modulus function," Analysis in Theory and Applications, vol. 27, no. 1, pp. 21-27, 2011.

[22] B. C. Tripathy, "Matrix transformation between some classes of sequences," Journal of Mathematical Analysis and Applications, vol. 206, no. 2, pp. 448-450, 1997.

[23] B. C. Tripathy, "On generalized difference paranormed statistically convergent sequences," Indian Journal of Pure and Applied Mathematics, vol. 35, no. 5, pp. 655-663, 2004.

[24] B. Altay and F. Başar, "Generalization of the sequence space $\ell(p)$ derived by weighted means," Journal of Mathematical Analysis and Applications, vol. 330, no. 1, pp. 147-185, 2007. 


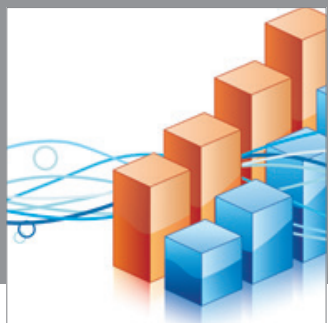

Advances in

Operations Research

mansans

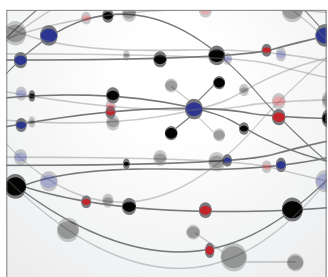

The Scientific World Journal
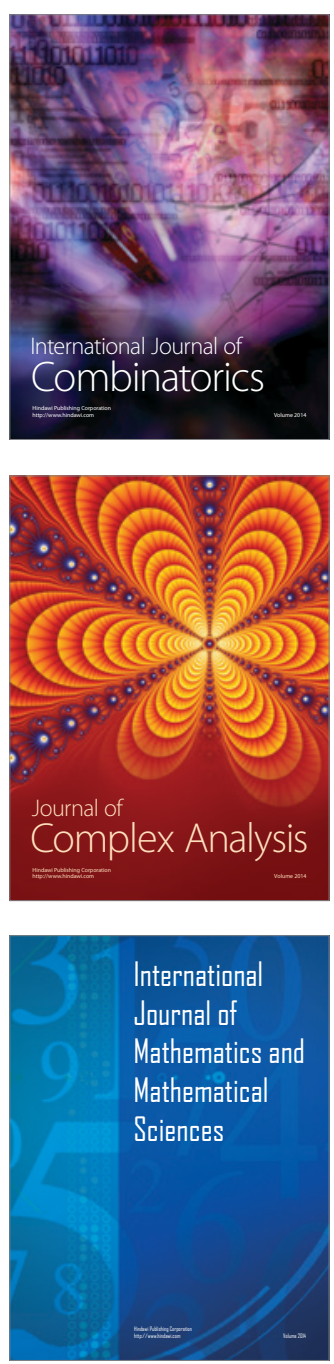
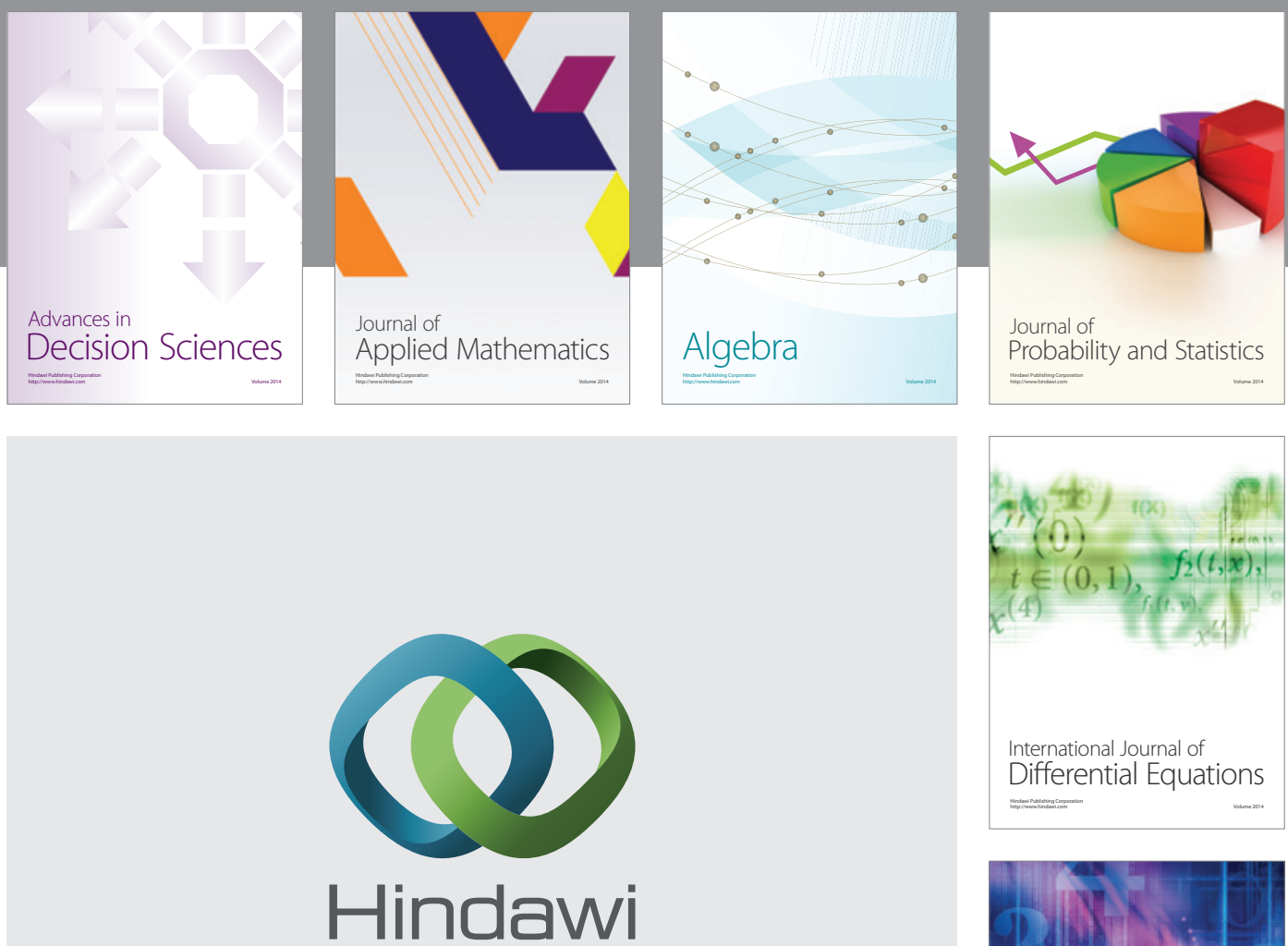

Submit your manuscripts at http://www.hindawi.com
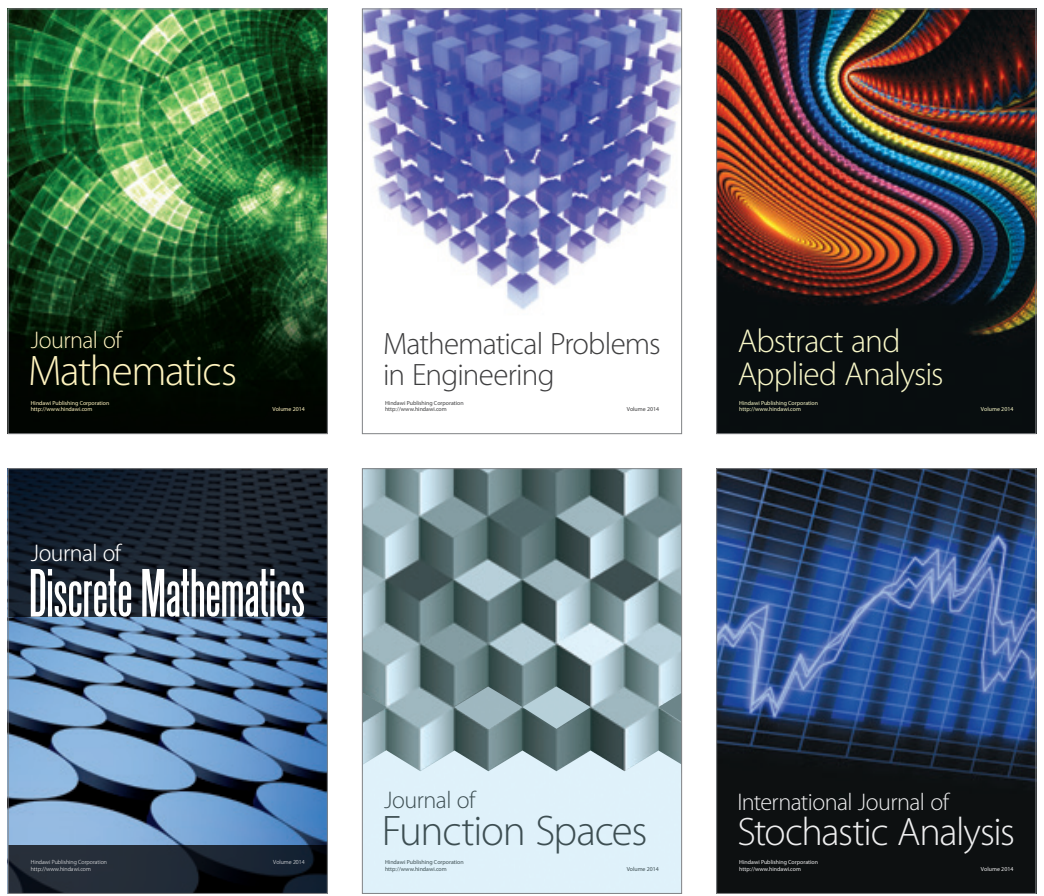

Journal of

Function Spaces

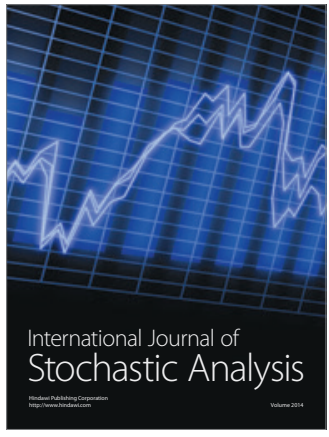

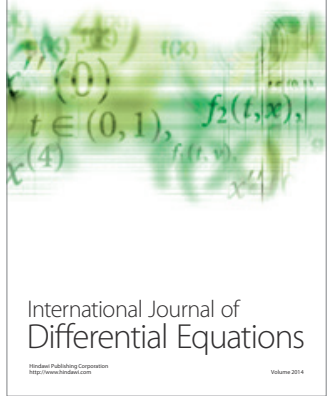
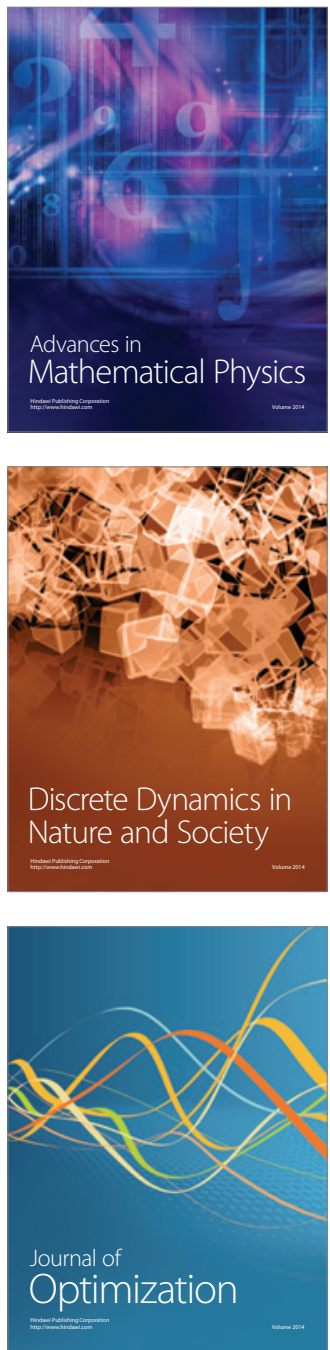